\title{
APPLICATION OF VITAMIN D IN DIFFERENT DOSAGE TO TREAT CHILDREN WITH ALLERGIC DISEASES
}

DOI: 10.36740/WLek202007114

\author{
Olexandra V. Tiazhka, Zoriana V. Selska \\ BOGOMOLETS NATIONAL MEDICAL UNIVERSITY, KYIV, UKRAINE
}

\begin{abstract}
The aim: To study the dynamics of the level of $25(\mathrm{OH}) \mathrm{D}, \mathrm{LL}-4, \mathrm{IL}-10$, and $\mathrm{lgG}$ in the blood serum of children with allergic diseases and to study the clinical effect of vitamin $\mathrm{D}_{3}$ administration $n$ different dosage in this category of patients.

Materials and methods: 153 children aged 3-16 with such allergic diseases as bronchial asthma, atopic dermatitis and allergic rhinitis have been examined. The level of $25(\mathrm{OH})$ D was determined using the electrochemiluminescence method, while the levels of IL-4, IL-10 and IgG were assessed using enzyme-linked immunoassay.

Results: In the contrasting of the initial level of $25(\mathrm{OH}) \mathrm{D}$ in the blood serum of patients after administration of 2,000 IU of vitamin $\mathrm{D}_{3}$ over 2 months, after summer and after treatment with cholecalciferol in higher doses (4,000-5,000 IU) over 2 months, significant difference was established between the indicators by the Friedman criterion $\left(\lambda^{2}=41.211 ; P<0.05\right)$. In the similar contrasting of IL-4 indicators, a significant difference between them was traced $(P<0.05)$ in the period of acute disease as well as the downward tendency in the period of remission. In the similar contrasting of IL-10 indicators, a significant difference between them was traced ( $P<0.05)$ in the acute period and in the period of disease remission. In the similar contrasting of IgG indicators, a downward tendency was traced in the period of acute disease and significant decrease $(\mathrm{P}<0.05)$ - in the period of disease remission. In the contrasting of $25(0 \mathrm{H}) \mathrm{D}$ and IL-4, IL-10 figures a strong reverse correlation relationship was traced. The therapeutic effect of the administration of vitamin $\mathrm{D}_{3}$ medication in different doses in children with allergic diseases was traced.

Conclusions: The data obtained shows that in the treatment of children with bronchial asthma, allergic rhinitis and atopic dermatitis the complex therapy should include vitamin $D_{3}$ medications in different doses within a long-term course of treatment.
\end{abstract}

KEY WORDS: children, allergic diseases, treatment, vitamin D

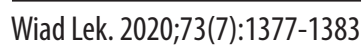

\section{INTRODUCTION}

Over the last decade the ideas about the normal concentration of vitamin D in human blood has changed. In 2011 the new classification of vitamin D-status in human organism was introduced, under which vitamin $\mathrm{D}$ deficit shall be established at the level of $25(\mathrm{OH}) \mathrm{D}$ in the blood serum below $50 \mathrm{nmole} / \mathrm{l}$, or below $20 \mathrm{ng} / \mathrm{ml}$, vitamin D deficiency shall be diagnosed at the level of 25(OH)D between 50-75 nmole $/ \mathrm{l}$, or $21-30 \mathrm{ng} / \mathrm{ml}$, while the level of $25(\mathrm{OH}) \mathrm{D}$ from 75 to $150 \mathrm{nmole} / \mathrm{l}$, or $31-85 \mathrm{ng} / \mathrm{ml}$ shall be considered to be within the norm [1]. According to the results of some scientific research, the best and most desirable level of $25(\mathrm{OH}) \mathrm{D}$ in the blood serum of human body shall be considered that of $36-48 \mathrm{ng} / \mathrm{ml}$ [2].

According to the results of large-scale studies, it has been established that hypovitaminosis $\mathrm{D}$ is characteristic of many residents of different countries of the world and is a widespread problem among adults and children $[3,4,5]$.

In particular, there are numerous scientific researches confirming involvement of vitamin $\mathrm{D}$ in the immune processes of human body $[6,7]$. It has been proven that hypovitaminosis D constitutes one of the factors causing not just development of the pathology of the musculo-skeletal system, but many diseases of other bodies and systems $[8,9,10,11]$.
It is known that development of such diseases as bronchial asthma, atopic dermatitis and allergic rhinitis takes place during pathological processes occurring in the immune system. According to the conclusions of scientific researches, it has been established that the key role in the allergic inflammation is played by IL-4, IL-5, IL-10, and IL-13 [12]. It is considered that IL- 4 is the main cytokine ensuring switching of B-lymphocytes to IgE synthesis, while IL-10 is its synergist. It is also known that $\operatorname{IgG}$ is the main class of antibodies, actively involved in the organism protection against bacteria, viruses and toxins, its intensified release by plasma cells starts only after repeated interaction with antigen. IgG includes several subpopulations: IgG1, IgG2, $\mathrm{IgG} 3$, and IgG4, and the latter, in its turn, participates in the allergic inflammation processes [13]. Due to this, in laboratory study of patients with allergic diseases attention should be paid to the level of the above cytokines and immunoglobulin in the patient blood.

Currently, many countries of the world regulate taking of vitamin $\mathrm{D}$ medications by people of different age categories. In 2012 the scientific and practical conference in Warsaw, where scientists from different countries of the world participated, approved recommended doses of vitamin D medications for the residents of Central Europe [14]. 
According to these recommendations, there are preventive doses of vitamin $\mathrm{D}$, that are taken on a daily basis throughout a year, but for summer months, with normal levels of $25(\mathrm{OH}) \mathrm{D}$ in the blood serum; marginal ones that will not lead to any side-effects when vitamin D medications are taken; treatment doses used in case of established vitamin $\mathrm{D}$ deficit and in case of different somatic diseases, including allergic diseases, since it is considered that hypovitaminosis $\mathrm{D}$ cna be one of the factors contributing to the development of allergic pathology $[15,16,17,18,19,20]$.

Over the recent years statistical research on the spread of allergic diseases among children and adults has testified to their rise throughout the world. That urges to do further studies in order to substantiate and develop prophylactic and treatment measures for this category of patients. Research of the clinical and laboratory efficiency of applying vitamin D medications in different dosage in children with allergic diseases are promising as far as development of a long-term treatment scheme with inclusion of this medication to the basic therapy for this category of patients is concerned.

\section{THE AIM}

To study the dynamics of the level of $25(\mathrm{OH}) \mathrm{D}$, IL-4, IL10 , and IgG in the blood serum of children with allergic diseases and to study the clinical effect of the application of vitamin $\mathrm{D}_{3}$ in different dosage for this category of patients.

\section{MATERIALS AND METHODS}

The study has been done in compliance with the provisions of the Declaration of Helsinki of the World Medical Association on the ethical principles for medical research involving human subjects (as of 2008), with the consent of the biotic commission (protocol of the meeting No. 76 as of December 25, 2013). The research has been performed on the basis of the written consent of the parents or guardians of each examined child to the research.

We have examined 153 children with allergic diseases, aged 3-16. As of the date of examination the children did not have any acute respiratory infections and chronic infection sites that could influence the results of the laboratory studies. There were 69 patients with bronchial asthma 69 $(46.9 \% \pm 4.2 \%), 18$ patients $(11.2 \% \pm 2.6 \%)$ had atopic dermatitis, 12 patients $(7.0 \% \pm 2.1 \%)$ had allergic rhinitis. There were 28 children with combined forms of allergic diseases (bronchial asthma and atopic dermatitis) $(18.2 \% \pm 3.2 \%)$, 26 patients $(16.8 \% \pm 3.1 \%)$ had both bronchial asthma and allergic rhinitis. Among all 123 clinical cases of bronchial asthma 11 cases $(8.9 \% \pm 2.8 \%)$ were the cases of persistent bronchial asthma of mild degree of severity, $89(72.4 \% \pm$ $4.3 \%)$ - persistent bronchial asthma of moderate degree of severity, and $23(18.7 \% \pm 2.3 \%)$ - of persistent bronchial asthma of grave degree of severity. Out of 46 clinical cases of atopic dermatitis $-12(26.1 \% \pm 3.8 \%)$ were of mild form, $25(54.3 \% \pm 2.5 \%)$ - of moderate severity, and $9(19.6 \%$ $\pm 4.3 \%)$ - of grave form of disease under the SCORAD index. Among 38 clinical cases of allergic rhinitis 26 cases $(68.4 \% \pm 3.6 \%)$ were the cases of round-the-year form, and $12(31.6 \% \pm 2.6 \%)$ - of the seasonal form.

Determination of the level of $25(\mathrm{OH}) \mathrm{D}$ in the blood serum was used as the indicator of sufficiency of vitamin $\mathrm{D}$ in the child organism. The level of $25(\mathrm{OH}) \mathrm{D}$ was determined using the electrochemiluminescence method at the Eleksys 2010 analysor (Roche Diaggnostics, Germany) under the Cobas system test at the SI 'D. F. Chebotariov Institute of Gerontology of the National Academy of Medical Sciences of Ukraine.

The level of IL-4, IL-10, and IgG was assessed using sets of reagents for enzyme-linked immunoassay in the immunology laboratory of SI 'Institute of Urology of the National Academy of Medical Sciences of Ukraine?

During statistical analysis the median (mean) (Me) was used as the central trend measure, while lower and upper quartiles were used for dispersion $\left(\mathrm{Q}_{1}\right.$ and $\left.\mathrm{Q}_{3}\right)$. To compare quantitative indicators between two groups of children with allergic diseases the Wilcockson indicator (W) was used, through determination of the criterion of Wilcockson signed ranks $(Z)$, the difference was significant at $\mathrm{P}<0.05$; in case of multi-time contrasting of the selection of children with allergic diseases after their treatment with cholecalciferol in different doses the Friedman criterion was applied $\left(\lambda^{2}\right)$, the difference was significant at $\mathrm{P}<0.05$. The relationship between the level of $25(\mathrm{OH}) \mathrm{D}$ in the blood serum and the level of allergic inflammation cytokines (IL-4, IL-10) in the blood of children with allergic diseases was studied using the correlation method, through determination of the Spearman's rank correlation coefficient $(\varphi)$.

\section{RESULTS}

As the result of the data obtained, the average level of 25 -hydroxycalciferol in children with allergic diseases made up $20.59 \mathrm{ng} / \mathrm{ml}\left(\mathrm{Me}=20.59 ; Q_{1}=16.63 ; Q_{3}=27.15\right)$

After prescription of vitamin $\mathrm{D}_{3}$ medication in the dose 2,000 IU daily over 2 months to children with allergic diseases, the mean level of $25(\mathrm{OH}) \mathrm{D}$ in the blood serum of patients after cholecalciferol intake made up $35.87 \mathrm{ng} / \mathrm{ml}$ $\left(\mathrm{Me}=35,87 ; Q_{1}=25,73 ; Q_{3}=41,56\right)$.

With the beginning of the sunny season the intake of vitamin $\mathrm{D}_{3}$ medications was terminated. After the summer period the mean rate of $25(\mathrm{OH}) \mathrm{D}$ in the blood serum was $35.13 \mathrm{ng} / \mathrm{ml}\left(\mathrm{Me}=35.13 ; Q_{1}=33.34 ; Q_{3}=43.88\right)$.

After the end of summer children with allergic diseases were prescribed higher doses of cholecalciferol - 4,000 IU daily during the disease remission and 5,000 IU daily during the acute period, with a 2-month course, combined with basic therapeutic measures applied over the period of remission and acute condition. After vitamin $\mathrm{D}_{3}$ intake the mean level of 25-hydroxycalciferol made up $46,35 \mathrm{ng} / \mathrm{ml}$ $\left(\mathrm{Me}=46,35 ; Q_{1}=43,45 ; Q_{3}=53,25\right)$.

In the contrasting of the initial level of $25(\mathrm{OH}) \mathrm{D}$ in the blood serum of patients after administration of 2,000 IU of vitamin $\mathrm{D}_{3}$ over 2 months, after summer and after the intake of cholecalciferol in higher doses (4,000-5,000 IU) over 2 


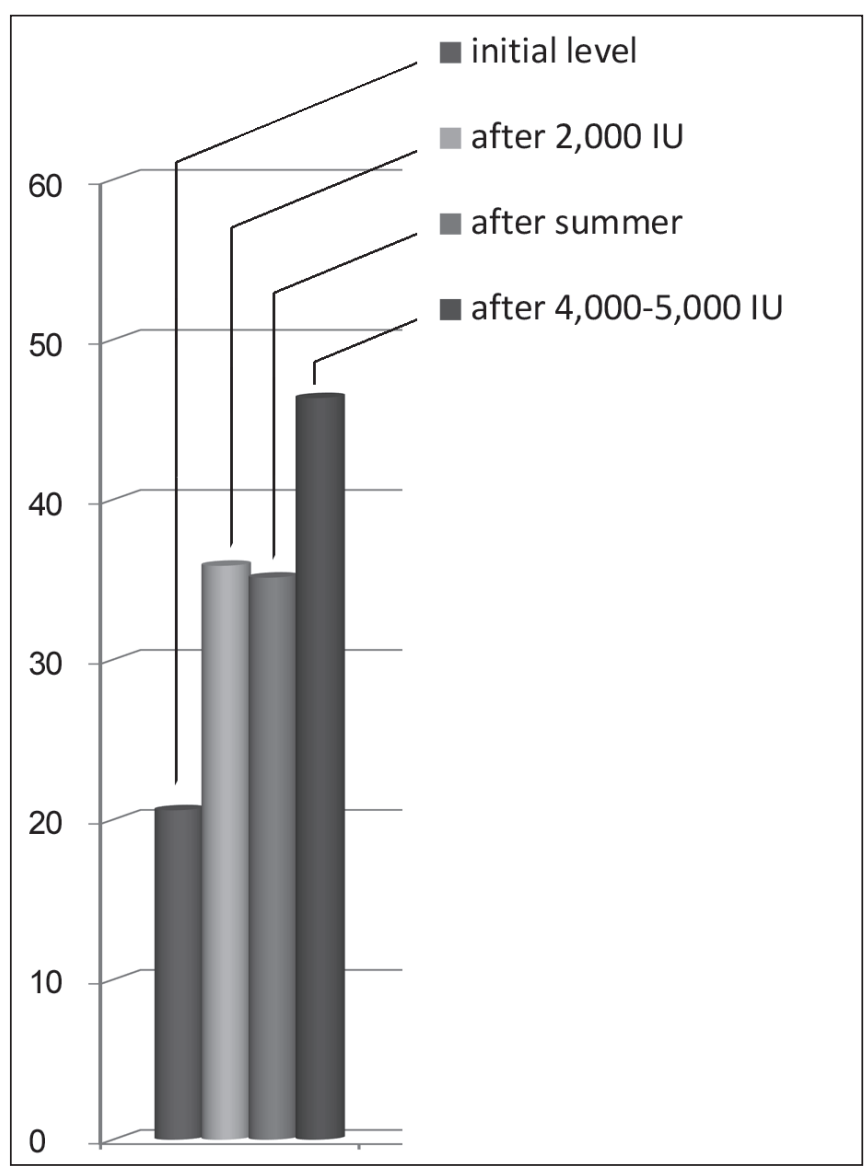

Fig. 1. Dynamics of the 25(OH)D level in the blood serum of children with allergic diseases depending on the administration of vitamin D3 medication and the season of the year, a significant difference as contrasted with the initial level, $\mathrm{p}<0.05$

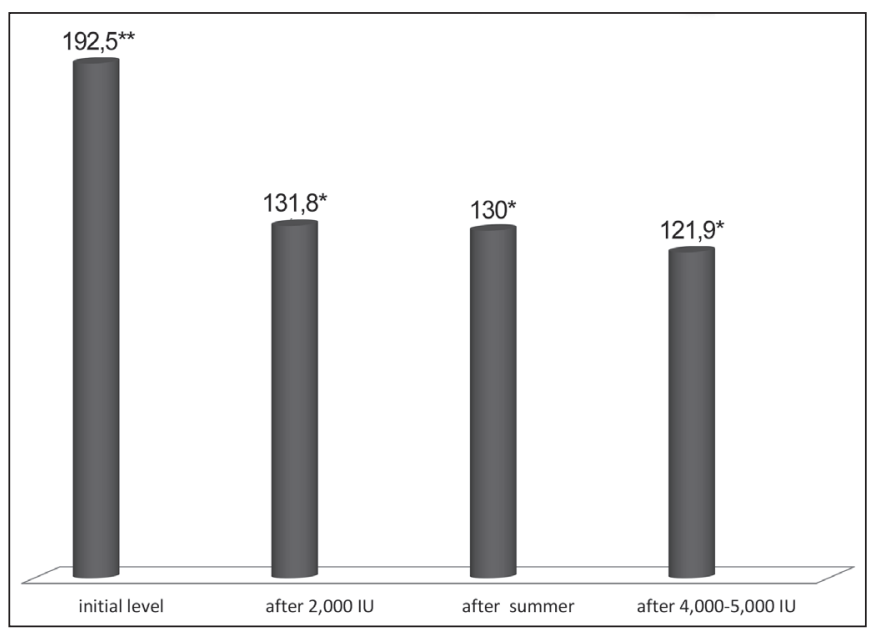

Fig. 2. Dynamics of IL-4 in children with allergic diseases in the acute period Notes: ${ }^{*}$ - significant difference as contrasted with the initial level, $p<0.05$ ** - significant difference as contrasted with the initial level, after 2,000 IU and after summer, $\mathrm{p}<0.05$.

months, a significant difference between the figures by the Friedman criterion was established $\left(\lambda^{2}=41.211\right.$; $\left.\mathrm{P}<0.05\right)$.

In the examination of the children under observation acute allergic disease was traced in $83(54.3 \pm 4.2 \%)$, and remission - in $70(45.7 \pm 4.2 \%)$ of children.

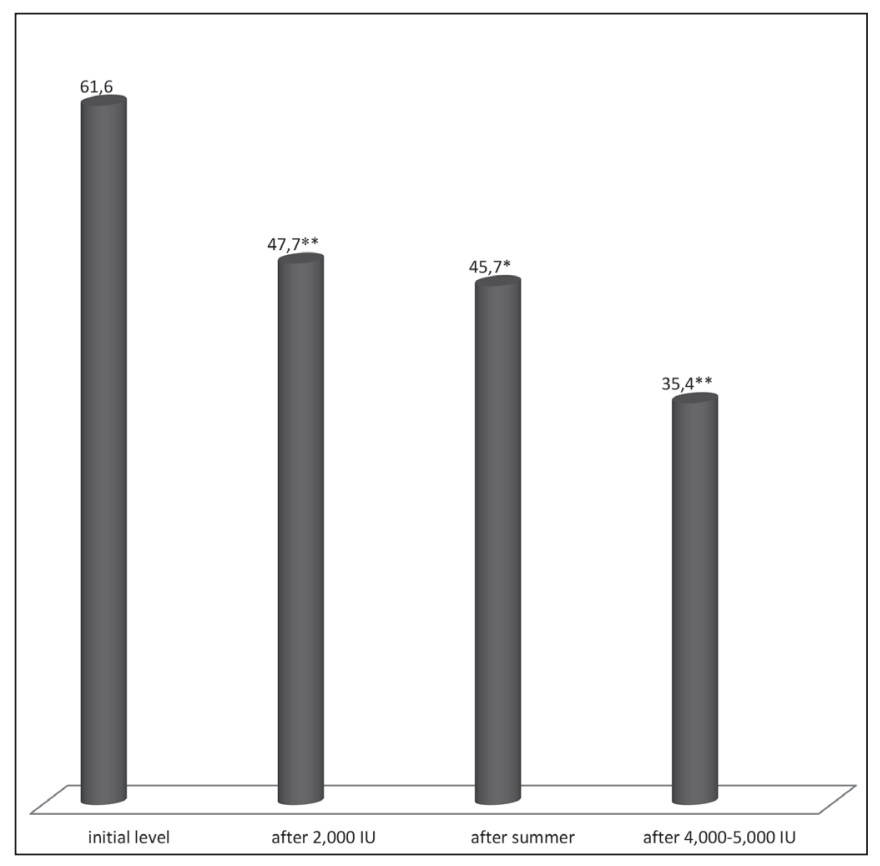

Fig. 3. Dynamics of IL-10 in children with allergic diseases in the acute period, ${ }^{*}$ - significant difference as contrasted with the initial level, after 2,000 IU and after summer, $\mathrm{p}<0.05$

Notes: * - significant difference as contrasted with the initial level, $p<0.05$ ** - significant difference as contrasted with the initial level, after 2,000 IU and after summer, $\mathrm{p}<0.05$.

Below are the results of determination of immunological indicators in the blood of children with allergic diseases over the period of acute disease. Thus, initial level of IL- 4 was $192.5 \mathrm{pg} / \mathrm{ml}$ $\left(\mathrm{Me}=192.5 ; Q_{1}=81.6 ; Q_{3}=257.6\right)$, after cholecalciferol administration in the dose of 2,000 IU over 2 months $-131.8 \mathrm{pg} / \mathrm{ml}$ $\left(\mathrm{Me}=131.8 ; Q_{1}=82.1 ; Q_{3}=205.5\right)$; after the summer period $130.0 \mathrm{pg} / \mathrm{ml}\left(\mathrm{Me}=130.0 ; Q_{1}=79.1 ; Q_{3}=175.6\right)$, after vitamin $\mathrm{D}_{3}$ medication administration in the dose of 4,000-5,000 IU over 2 months $-121.9 \mathrm{pg} / \mathrm{ml}\left(\mathrm{Me}=121.9 ; Q_{1}=70.0 ; Q_{3}=143.9\right)$. In the contrasting of IL- 4 figures a significant difference was established between them $(\mathrm{P}<0.05)$ (Fig. 2).

The initial level of IL- 10 in children with allergic diseases in theacuteperiod was61.6pg/ml $\left(\mathrm{Me}=61.6 ; Q_{1}=53.4 ; Q_{3}=77.9\right)$, after intake of vitamin $\mathrm{D}_{3}$ medication in the dose of 2,000 IU daily over 2 months $-47.7 \mathrm{pg} / \mathrm{ml}\left(\mathrm{Me}=47.7 ; Q_{1}=40.4\right.$; $\left.Q_{3}=54.9\right)$, after summer $-45.7 \mathrm{pg} / \mathrm{ml}(\mathrm{Me}=45.7$; $\left.Q_{1}=38.2 ; Q_{3}=53.8\right)$, after cholecalciferol administration in the dose of 4,000-5,000 IU - 35.4 pg/ml $(\mathrm{Me}=35.4$; $\left.Q_{1}=30.2 ; Q_{3}=44.5\right)$. In the contrasting of IL-10 figures a significant difference was established between them $(\mathrm{P}<0.05)$ (Fig. 3).

The initial IgGlevel over the acute period made up $28.1 \mathrm{~g} / \mathrm{l}$ $\left(\mathrm{Me}=28.1 ; Q_{1}=15.1 ; Q_{3}=31.1\right)$, after administration of vitamin $\mathrm{D}_{3}$ medication in the dose of 2,000 IU over 2 months $-27.6 \mathrm{~g} / \mathrm{l}\left(\mathrm{Me}=27.6 ; Q_{1}=11.1 ; Q_{3}=32.2\right)$, after summer - $21.7 \mathrm{~g} / \mathrm{l}\left(\mathrm{Me}=21.7 ; Q_{1}=14.7 ; Q_{3}=27.8\right)$, after cholecalciferol administration in the dose of 4,000-5,000 IU over 2 months $-10.2 \mathrm{~g} / \mathrm{l}\left(\mathrm{Me}=10.2 ; Q_{1}=9.4 ; Q_{3}=14.4\right)$. In the contrasting of IgG levels in children with allergic diseases a downward trend could be traced (Fig. 6). 


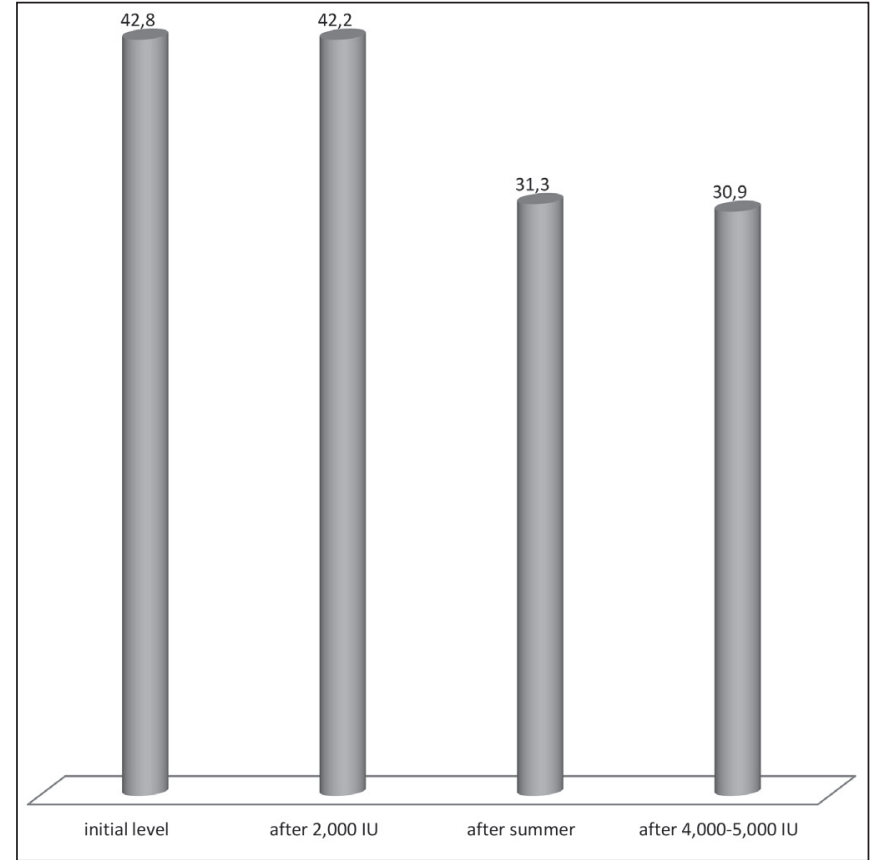

Fig. 4. Dynamics of the IL-4 level in children with allergic diseases in the remission period.

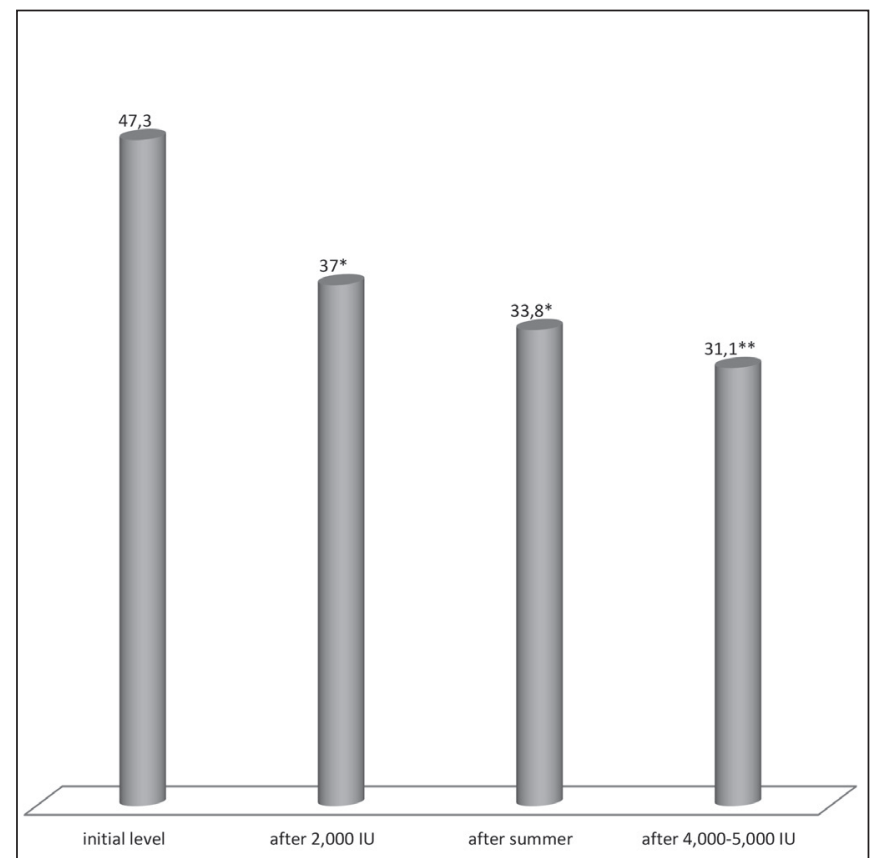

Fig. 5. Dynamics of IL-10 in children with allergic diseases in the period of disease remission

Notes: * - significant difference as contrasted with the initial level, $p<0.05$

** - significant difference as contrasted with the initial level, after 2,000 IU and after summer, $\mathrm{p}<0.05$

Below are the results of determination of immunological indicators in the blood of children with allergic diseases in the period of disease remission. The initial level of IL- 4 in the period of disease remission in children with allergic diseases made up $42.8 \mathrm{pg} / \mathrm{ml}\left(\mathrm{Me}=42.8 ; Q_{1}=25.6 ; Q_{3}=111.2\right)$, after cholecalciferol administration in the dose of $2,000 \mathrm{IU}$ daily over 2 months $-42.2 \mathrm{pg} / \mathrm{ml}\left(\mathrm{Me}=42.2 ; Q_{1}=28 ; Q_{3}\right.$ = 93), after the summer period $-31.3 \mathrm{pg} / \mathrm{ml}(\mathrm{Me}=31.3$;

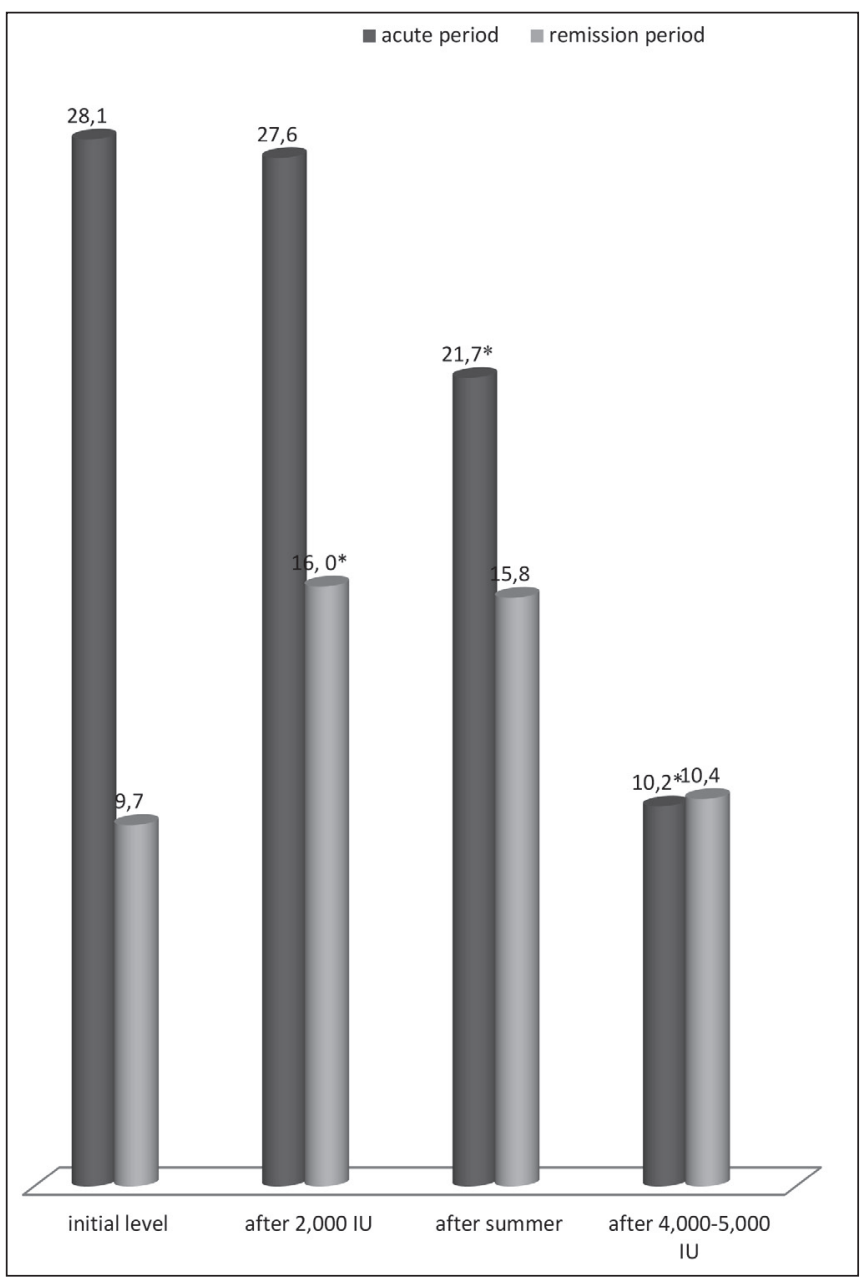

Fig. 6. Dynamics of lgG in children with allergic diseases in the acute period and in the period of disease remission.

Notes: * - significant difference as contrasted with the initial level, $p<0.05$.

$Q_{1}=24.5 ; Q_{3}=86.3$ ), after intake of vitamin $\mathrm{D}_{3}$ medication in the dose of 4,000-5,000 IU daily over 2 months - 30.9 $\mathrm{pg} / \mathrm{ml}\left(\mathrm{Me}=30.9 ; Q_{1}=20.1 ; Q_{3}=68\right)$, a trend to decrease in the level of IL- 4 in the blood of children in the period of disease remission could be traced (Fig. 4).

The initial level of IL-10 in children with allergic diseases made up $47.3 \mathrm{pg} / \mathrm{ml}\left(\mathrm{Me}=47.3 ; Q_{1}=24.9 ; Q_{3}=62.2\right)$, after administration of vitamin $\mathrm{D}_{3}$ medication in the dose of 2,000 IU daily over 2 months $-37.0 \mathrm{pg} / \mathrm{ml}\left(\mathrm{Me}=37 ; Q_{1}=24.4 ; Q_{3}=59.9\right)$, after the summer period $-33.8 \mathrm{pg} / \mathrm{ml}\left(\mathrm{Me}=33.8 ; Q_{1}=16.1 ; Q_{3}=54.7\right)$, after administration of 4,000-5,000 IU of cholecalciferol a day within a 2-month course-31.1 pg/ml $\left(\mathrm{Me}=31.1 ; Q_{1}=10.9 ; Q_{3}=50\right)$. In the contrasting of IL-10 figures a significant difference between them was established $(\mathrm{P}<0.05)$ (Fig. 5).

The initial level of IgG in the period of remission constituted $9.7 \mathrm{~g} / \mathrm{l}\left(\mathrm{Me}=9.7 ; Q_{1}=8.1 ; Q_{3}=20.1\right)$; after administration of vitamin $\mathrm{D}_{3}$ medication in the dose of 2,000 IU over 2 months - $16.0 \mathrm{~g} / \mathrm{l}\left(\mathrm{Me}=16.0 ; Q_{1}=9.7 ; Q_{3}=33.2 \mathrm{~g} / \mathrm{l}\right)$; after summer - $15.8 \mathrm{~g} / \mathrm{l}\left(\mathrm{Me}=15.8 ; Q_{1}=12 ; Q_{3}=31.4\right)$; after administration of cholecalciferol in the dose of 4,000-5,000 IU over 2 months - $10.4 \mathrm{~g} / \mathrm{l}\left(\mathrm{Me}=10.4 ; Q_{1}=9 ; Q_{3}=12.5\right)$. In the contrasting of IgG figures a significant difference between them was established $(\mathrm{P}<0.05)$ (Fig. 6). 
Table I. The course of allergic diseases before and after long-term administration of vitamin D3 in the complex of treatment and rehabilitation activities in children

\begin{tabular}{ccc}
\hline Feature & Prior to vitamin $\mathbf{D}_{\mathbf{3}}$ administration & ${\text { After vitamin } \mathbf{D}_{\mathbf{3}} \text { administration }}$ \\
\hline Frequency of acute periods over the year & $10-12$ times & $5-7$ times \\
\hline $\begin{array}{c}\text { Frequency of acute periods over the year with } \\
\text { hospitalization }\end{array}$ & $5-10$ times & $3-7$ times \\
\hline ARI over the year & $7-8$ times & $4-5$ times \\
\hline Duration of acute periods & $10-14$ days & $8-6$ days \\
\hline Intoxication & Present & Almost non-available \\
\hline
\end{tabular}

In case of individual contrasting of the dynamics of the level of 25(OH)D in each child and the dynamics of IL-4, IL-10 in the blood against cholecalciferol arrival in the body from an endogenic and exogenic source in different periods of the disease, it was established that if the level of $25(\mathrm{OH}) \mathrm{D}$ in the blood serum goes up, the level of IL-4 and IL-10 goes down. Since for each child the fluctuations of IL-4, IL-10 and 25(OH)D were within the individual range, calculation of the correlation factor was made in accordance with each child's indicator, in particular, Spearman's rank correlation coefficient varied $(0.7 \leq \varphi \leq 1)$, which fact testifies to a strong reverse correlation relationship.

In the course of the study, in order to maintain normal $25(\mathrm{OH}) \mathrm{D}$ level in the blood serum in children with allergic diseases after cholecalciferol prescription in higher doses, children with allergic diseases were recommended to continue intake of vitamin $\mathrm{D}_{3}$ medication in the preventive dose - 1,000 IU daily over the year, but for summer months. All patients were kept under our observation over 1.5 years.

In the course of the study the therapeutic effect of administration of vitamin $\mathrm{D}_{3}$ medication in children with allergic diseases could be traced, which fact is proven by the reduced number of acute allergic disease episodes and their severity over the year, reduced duration of acute condition, frequency of hospitalization due to the main disease over the year, reduced number of cases of acute respiratory infections over the year. In children with atopic dermatitis, when cholecalciferol was administered, reduced areas of skin lesion during the acute condition could be traced, as well as quick restoration of the skin cover in the period of reconvalescence, reduced number of secondary elements and skin dryness. Besides that, improved course of the main disease was also accompanied by improved general condition of patients, manifested in increased physical and mental activity, reduced manifestation of quick fatigue and weakness, reduced number of headache and dizziness episodes, improved appetite and sleep. The results of the clinical picture of patients are provided in table 1 . It should be pointed out that a better manifested therapeutic effect could be traced when vitamin $\mathrm{D}_{3}$ was administered in higher doses (4,000-5,000 IU) during 2 months in children with allergic diseases.

\section{DISCUSSION}

Taking into account due level of 25(OH)D in human blood serum and the results of the initial level of 25-hydroxycalciferol in children with allergic diseases, significant vitamin D deficiency in the organisms of patients of this category has been traced. Thus, it may be considered that children with allergic diseases are prone to develop hypovitaminosis $\mathrm{D}$.

In order to achieve normal level of $25(\mathrm{OH}) \mathrm{D}$ in the blood serum of patients, all children with allergic diseases regardless of their age were prescribed vitamin $\mathrm{D}_{3}$ medication in the dose of 2,000 IU daily over 2 months. After that, on assessment of the organism provision with vitamin $\mathrm{D}$ in children with allergic diseases, normal level of $25(\mathrm{OH})$ $\mathrm{D}$ in the blood serum of patients was established. After two months of cholecalciferol intake the clinical effect in children with allergic diseases was difficult to assess due to short period of observation.

After the summer period the $25(\mathrm{OH}) \mathrm{D}$ level in the blood serum of children under examination remained almost the same. Taking into account the data on vitamin D metabolism, it may be assumed that vitamin D arriving to the body due to the medication intake before summer, over the summer period (3 months) should have left the organism, and the level of 25(OH)D in the blood serum of patients after summer should have gone back to its initial value. Obvious is the fact that synthesis of vitamin under the effect of solar UV-radiation can keep 25(OH)D in the blood serum of children at an adequate level after vitamin $\mathrm{D}_{3}$ medication is administered. It should be indicated that no considerable improvement in the clinical course of allergic diseases could be traced.

In order to achieve the best possible level of $25(\mathrm{OH}) \mathrm{D}$ in the blood serum $(36-48 \mathrm{ng} / \mathrm{ml})$ of all patients and to raise the therapeutic effect for children with allergic diseases, higher doses of cholecalciferol were prescribed $-4,000$ IU a day during remission of the disease and 5,000 IU a day during the period of acute disease in the course of 2 months, together with the basic treatment activities carried out in the periods of remission and acute disease. Higher doses of cholecalciferol were prescribed due to the recommendations on vitamin D medication administration in the residents of Central Europe. After that in no children the level of 25(OH)D in the blood serum was established as higher than the normal value (> $80 \mathrm{ng} / \mathrm{ml})$, and no clinical signs of hypervitaminosis $\mathrm{D}$ were identified, also the best possible level of $25(\mathrm{OH}) \mathrm{D}$ in the blood serum of patients was achieved. Thus, it may be considered that prescription of higher doses of cholecalciferol within the above course for children with allergic diseases is safe.

Laboratory data related to provision of children with allergic diseases with vitamin $\mathrm{D}$ in the period of administration of its preparation in different doses shows that 
cholecalciferol intake leads to increased level of 25(OH)D in the blood serum of patients, and the higher the vitamin $\mathrm{D}_{3}$ medication dose, the higher the level of 25-hydroxicalciferol in the blood of patients.

To exclude the effect of the disease period on the level of immunological indicators in the blood of each patient they were measured over the same period of disease (remission or acute condition). To achieve this goal, children with allergic diseases were divided into two groups: children examined in the period of acute condition and children whose level of immunological indicators was measured in the period of remission.

It is known that IL- 4 and IL-10 are cytokines of the immune system, that actively participate in the allergic inflammation processes, and then their increase in the blood of patients can be traced. Taking into account the results obtained, it may be assumed that vitamin $\mathrm{D}$ is involved in the decrease of allergic inflammation over the period of acute BA, allergic rhinitis and atopic dermatitis, since significant reduction in the level of IL-4, IL-10 and the trend to IgG decrease in the blood of children in the period of acute disease could be traced if vitamin $\mathrm{D}_{3}$ was administered in different doses. If the IgG - IgG4 subpopulation is considered to be involved in the allergic inflammation, it may be assumed that the level of total IgG decreases as the result of this faction.

It may also be assumed that vitamin $\mathrm{D}$ reduces organism sensibilization in the period of remission of the allergic disease, which fact is confirmed by the trend to reduced level of IL-4, significant decrease of IL-10 and IgG content in the blood of children in the period of disease remission, if cholecalciferol is administered in different doses. In the contrasting of the indicators of the dynamics in the level of 25(OH)D and IL-4, IL-10 in the blood of every child a strong reverse correlation relationship was traced between the level of 25(OH)D and allergic inflammation cytokines (the higher the level of 25(OH)D, the lower the level of IL-4 and IL-10), which also confirms involvement of vitamin $\mathrm{D}$ in allergic inflammation decrease in different disease periods (acute condition, remission).

After the clinical effect was assessed in the period of cholecalciferol administration in different doses in children with allergic diseases, considerable improvement in the course of the disease was traced. This data proves the need for long-term administration of vitamin $\mathrm{D}_{3}$ medication in this category of patients. The commencement of improved course of the main disease and the best possible level of $25(\mathrm{OH}) \mathrm{D}$ in the blood serum of patients could be traced after cholecalciferol prescription in higher doses (4,000-5,000 IU). It should be considered that short-term courses of treatment with vitamin $\mathrm{D}_{3}$ in higher doses at the controlled level of $25(\mathrm{OH}) \mathrm{D}$ in the blood serum of patients should be included in the long-term cholecalciferol administration in children with allergic diseases. Reduced pathological symptoms that are not patogmonic for an allergic disease but may accompany it and characterize the overall condition of patients also point to the positive clinical effect of vitamin D. Also, reduced number of acute respiratory disease episodes, which often trigger the development of acute allergic disease, over the year in children with allergic diseases should be pointed out, which fact also proves the need for cholecalciferol administration in this category of patients.

\section{CONCLUSIONS}

Thus, the results of the research show that vitamin D is involved in the immune system processes aimed at reduced allergic inflammation in the period of acute disease and disease remission, since significant reduction or a trend to reduced level of immunological indicators IL-4, IL-10, and IgG in the blood serum of children with allergic diseases in the period of disease remission and acute disease in case of their treatment with vitamin $\mathrm{D}_{3}$ have been traced The reverse correlation has been established between the level of $25(\mathrm{OH}) \mathrm{D}$ and IL4, IL-10 in the blood serum of patients. Taking into account the data obtained, we consider that while in the treatment of children with bronchial asthma, allergic rhinitis and atopic dermatitis the complex therapy should include vitamin $\mathrm{D}_{3}$ medications with a long course of treatment in different doses, including higher doses, at the controlled level of 25(OH)D in the blood serum of patients. That will contribute to improved course of the main disease and reduced manifestations of asthenoneurotic syndrome. The results of the research testify to the need for further scientific research into possible administration of vitamin $\mathrm{D}_{3}$ in the treatment and prevention of allergic diseases in children.

\section{REFERENCES}

1. Holick M.F., Binkley N.C., Bischoff H.A. et al. Evalution, treatment and prevention of vitamin D deficiency: an Endocrine Society Clinical Practice Guideline. J Clin Endocrinol Metab 2011; 96 (7): 1911-1919.

2. Bischoof-Ferrari H.A. Optimal serum 25-hydroxyvitamin D levels for multiple health outcomes. Adv Exp Med Biol 2008; 624: 55-71.

3. Chung I.H., Kim H.J., Chung S. et al. Vitamin D Deficiency in Korean children: prevalence, risk and relationship with parathyroid hormone levels. Ann Pediatr Endocrinol Metab 2014; 19 (2): 86-90.

4. Young E. R., Kim B. R., Choi W. B. et al. Vitamin D deficiency in chidren ages 6 to 12 years: single center's experience in Busan. Ann Pediatr Endocrinol Metab 2016; 21 (3): 149-154.

5. Cediel G., Pacheco-Acosta J., Castillo-Duran C. Vitamin D deficiency in pediatric clinical practice. Arch Argent Pediatr 2018; 116 (1):75-81.

6. Wang Z., Wang Y., Xu B.et al. Vitamin D improves immune function in immunosuppressant mice induced by glucocorticoid. Biomed Rep 2017; $6(1): 120-124$.

7. Medrano M., Carillo-Cruz E., Montero I.et al. Vitamin D: Effect on haematopoesis and immune system and clinical applications. Int Mol Sci 2018; 19 (9): 2663.

8. Azrielant S., Shoenfeld Y. Vitamin D and autoimmune diseases. Indian J Rheumatol 2017; 12: 219-222.

9. Dimitrov V., White J. H.. Calcium, vitamin D and immunity in the colon. Am J Clin Nutr 2016; 103 (5): 1195-1196.

10. Both D.R., Ding N., Parnell G.P. et al. Cistromic and genetic that the vitamin $D$ receptor mediates susceptibility to latitude-dependent autoimmune diseases. Genes Immun 2016; 17 (4): 213-219. 
11. Petersen R.A., Damsgaard C.T., Dalskov S.M. et al. Vitamin D status and its determinants during autumn in children at northern latitudes: a cross-sectional analysis from the optimal well-being, development and health for Danish children through a healthy New Nordic Diet (OPUS) School Meal Study. Br J Nutr 2016; 115 (2): 239-250.

12. Gour N., Wills-Karp M.. IL-4 and IL-13 signaling in allergic airway disease. Cytokine 2015; 75 (1): 68-78.

13. Lawrence M.G., Steinke J.W., Borish L.. Cytokine-targeting biologics for allergic diseases. Ann Allergy Asthma Immunol 2018; 120 (4):376-381.

14. Pludovski P., KarczmarewiczE., Bayer M. et al. Practical guidelines for the supplementation of vitamin D and the treatment of deficits in Central Europe - recommended vitamin D intakes in the general population and groups at risk of vitamin D deficiency. Endokrynol Pol 2013; 64 (4): 319-327.

15. Cairncross C., Grant C., Stonehouse W. et al. The relationship between vitamin D status and allergic diseases in New Zealand preschool children. Nutrients 2016; 8 (6): 326.

16. Del Giudice M., Allegorico A. The role of vitamin $D$ in allergic diseases in children. J Clin Gastroenterol 2016; 50 (2): 133-135.

17. Hang Y.Y., Forno E., Celedon J. C. Vitamin D insufficiency and asthma in a US Nationwide study. J Allergy Clin Immunol Pract 2017; 5 (3):790-796.

18. Kim Y.H., Kim K.W., Kim M.J. et al. Vitamin D levels in allergic rhinitis: a systematic review and meta-analysis. Pediatr Allergy Immunol 2016; 27 (6): 580-590.

19. Aryan Z., Rezaei N., Camargo C.A. Vitamin D status, aeroallergen sensitization, and allergic rhinitis: a systematic review and metaanalysis. Int Rev Immunol 2017; 36 (1): 41-53.

20. Huang C.M., Lara-Corrales I., Pope E. Effects of vitamin D levels and supplementation on dermatitis: a systematic review. Pediatr Dermatol 2018; 35 (6): 754-760.
The article is part of the scientific research of Department of pediatrics №1 Bogomolets National Medical University - The study of pathogenetic mechanisms for the implementation of infectious-respiratory, allergic and metabolic pathology in children, taking into account the genetic characteristics of the constitution and adverse factors, № 0113000059.

\section{ORCID and contributionship:}

Olexandra V. Tiazhka: 0000-0001-9223-5496 A,E,F

Zoriana V. Selska: 0000-0001-8582-695X B,C,D

\section{Conflict of interest:}

The Authors declare no conflict of interest.

\section{CORRESPONDING AUTHOR \\ Zoriana V. Selska}

Bogomolets National Medical University

13 Taras Shevchenko Boulevard, 01601 Kyiv, Ukraine

tel: +380982117461

e-mail:zoryana_888@ukr.net

Received: 11.10 .2019

Accepted: 20.04 .2020

A - Work concept and design, B - Data collection and analysis, C - Responsibility for statistical analysis, D -Writing the article, $\mathbf{E}$-Critical review, $\mathbf{F}$ - Final approval of the article 